\title{
Everyday Energy Politics in Central Asia and the Caucasus: Citizens' Needs, Entitlements, and Struggles for Access, by David Gullette and Jeanne Féaux de la Croix
}

\author{
REVIEWEd by JeREMY TASCH* \\ Department of Geography and Environmental Planning, Towson University, US
}

Evocative words and phrases such as "Great Game," "Color Revolutions," "Vast oil and gas wealth," and increasingly "China's Belt and Road Initiative" commonly prefix discussions of current events in the Caucasus and Central Asia, in both scholarly journals and more general news accounts. Feature articles and occasional clips on the evening television news in the United States highlight an extended region popularly reduced to references to Marco Polo, Genghis Khan, and the Silk Road. For centuries, the extended region attracted the world's shifting superpowers as they sought geopolitical advantage, access to natural resources, or military bases from which to influence adjacent regions. Largely omitted from past accounts and present descriptions are the daily struggles and everyday politics as experienced by residents of the extended region.

Social scientists interested in the Caucasus and Central Asia have often attempted to combine regional analyses, particularly regarding politics, demography, and urbanization, with macroeconomic studies, frequently oriented to resource and trade economics. In this manner, scholars have been working to make sense of the ways that underlying historical palimpsests and evolving political and economic relationships influence these regions. But differing from the approaches used by many of these investigations, social anthropologists David Gullette and Jeanne Féaux de la Croix, in their edited collection of seven previously published articles, Everyday Energy Politics in Central Asia and the Caucasus [sic] ${ }^{1}$ : Citizens' Needs, Entitlements, and Struggles for Access, emphasize first-hand observations and intensive field-based research. As they offer in the book's introduction (pg. 11), "The intersection of the state, companies and people's political expectations, coupled with their everyday energy needs and strategies are important aspects of people's experiences." The volume's focus on "people's experiences" of energy politics is where this collection contributes to other work that explores the Caspian Regions' hydrocarbons (cf. Palazuelos, Enrique and Rafael Fernandez 2012 [1]; Pleines, Heiko, and Ronja Wöstheinrich 2016 [2]), other areas' relative energy poverty, and concomitant challenges (cf. Bliss 2013 [3]; Freeman 2018 [4]).

The introduction and the seven chapters of the book each explore-with the exception of the first chapter that is regionally focused on Afghanistan-how the legacies of Soviet energy distribution together with new constellations of political, economic, and energy concerns affect residents of the south Caucasus and Central Asia. The authors approach this issue from a variety of disciplinary

\footnotetext{
* Received: 22 Jul 2019 Accepted: 22 Jul 2019 Published: 9 Aug 2019 Journal of Asian Energy Studies (2019), Vol 3, 40-44, doi:10.24112/jaes.030004

${ }^{1}$ As this volume includes one chapter that explores the energy challenges in two communities in Armenia and Georgia, and another chapter focused on Baku, Azerbaijan, South Caucasus would be more appropriate than the more geographically comprehensive "Caucasus."
} 
perspectives including those of the anthropologist, environmentalist, political scientist, historian, economist, and geographer. Indeed, each chapter previously appeared in a multidisciplinary issue of Central Asian Survey (volume 33, issue 4, December 2014), and as their introduction did for the special issue, Gullette and de la Croix's introduction for this Routledge re-print attempts to provide a broad context to match the breadth of the subsequent chapters. For readers unfamiliar with the history of energy production and distribution in the south Caucasus and Central Asia, the editors in just over three pages offer a broad historical journey through some of the energy challenges, accomplishments, and mistakes of later Czarist Russia, and early, mid- and late-Soviet periods.

From here, Gullette and de la Croix set the tone for the remainder of their edited volume by offering a very brief discussion for how this material inheritance continues to influence residents' energy consumption expectations and encounters. The legacies of past practices and physical infrastructure have quite understandably led to general expectations among residential consumers that energy is-or should be-an entitlement. From the still historically recent Soviet past, many residents across Eurasia judge that provision of free-or at a minimum affordable-and dependable energy is a state's responsibility. In hydrocarbon-wealthy nations, including Azerbaijan (chapter 6), and Kazakhstan (chapter 5), as well as in energy-challenged nations, such as Afghanistan (chapter 1), Kyrgyzstan (chapters 3 and 7), and Tajikistan (chapter 8) residents' conviction that energy resources are part of the nation's endowment may not align with their governments' policies that treat energy as a marketable commodity. When these conditions are not met-the case in varying degrees across Eurasia-citizenry feelings of injustice and their resulting reactions differ dramatically, which can be compounded when marginalization, corruption, and rent-seeking practices are involved.

Having offered a glimpse at some of the general historical settings and an impression of contemporary specificities Everyday Energy Politics begins more directly to engage with the ways energy politics are experienced and practiced with Melissa Kerr Chiovenda's chapter 1, "The Illumination of Marginality: how Ethnic Hazaras in Bamyan, Afghanistan, Perceive the Lack of Electricity as Discrimination." Introduced with a brief quote from a friend and resident of central Afghanistan, Chiovenda's chapter explores the real and perceived ways that ethnic Hazaras in Bamyan, Afghanistan are excluded from access to state-provided electricity. Beginning and concluding her narrative on Alakain ("Lantern") Square-the fitting location for a sculpture of a lantern-Chiovenda employs the lantern trope to explore the multiple layers of meaning that access to electricity has for an ethnic minority that continues to experience marginalization.

From Afghanistan the volume moves westward across Central Asia to Amanda Wooden's chapter three, "Kyrgyzstan's Dark Ages: Framing and the 2010 Hydroelectric Revolution." Mass demonstrations that occurred as part of Georgia's "Rose Revolution" in 2003, then Ukraine's 2004-2005 "Orange Revolution," the Kyrgyz Republic's 2005 "Tulip Revolution," and more recently Armenia's "Velvet Revolution" have helped co-join color, flowers, woven fabric and revolution to the extended Caucasus and Central Asian regions. To this vibrant lexicon, for the Kyrgyz case Wooden adds "Hydroelectric Revolution" to describe what has alternately been referred to as the "Second Kyrgyz Revolution" and the "April Events" of 2010. Heavily influenced by political ecology, Wooden traces residents' mistrust of and frustration with opaque official explanations for hydroenergy management and electricity shortages to help reveal a number of compounding influences that help to "shed light" on reasons for the 2010 revolution in Kyrgyzstan. Moving across Central Asia and crossing the Caspian, Jason Strakes, in chapter four, "Resource Dependence and Measurement Technology: International and Domestic Influences on Energy Sector Development in Armenia and Georgia," explores how gas sector reform affected consumers in Armenia and Georgia, two neighboring south Caucasus societies dependent on international 
natural gas supplies. While the measurement of energy consumption has been considered by the international policy community, the author investigates residential "dependency and innovation in gas metering technology" as the "essential link" (pg. 61) between the natural gas sector and individual end users. He arrives at this conclusion largely through empirical data collected in an Armenian provincial capital, Varadez, and in Georgia's national capital, Tbilisi. These cases provide revealing glimpses into how residential energy users in two south Caucasus communities have been navigating the challenges of outmoded infrastructure and energy resource dependence. The choice of Tbilisi and Varadez are indeed instructive, notwithstanding the author's equivocal assertion that they are comparative.

Chapter five moves back across the Caspian with Philipp Frank Jäger's "Flows of Oil, Flows of People: Resource-extraction Industry, Labor Markets and Migration in Western Kazakstan." As the Soviet Union disbanded, western energy companies eagerly pursued opportunities across the rebounding region to establish favorable production sharing agreements, and advantageous leasing and joint venture arrangements. Yet despite economic tumult and legislative uncertainty among the newly independent states, and international corporations' race to assert control over newly accessible hydrocarbon resources, outright foreign purchase of oil and natural gas deposits and domestic production companies was rare and indeed generally non-existent. This is significant to note, because Jäger curiously offers in his chapter's introduction, "all the country's [Kazakhstan] oil fields and formerly state-owned companies were sold to foreign companies at a bargain." Jäger utilizes ethnographic methods to interact with economic migrants and their families in order to better link global energy demand with workers' lives. This approach holds exciting potential to reveal precisely the intent of this volume's title, to explore "everyday energy politics" as voiced by individuals who too often are without a voice. For residents living in resource-wealthy Kazakhstan, the unreliable benefits of oil development understandably generate equivocal opinions. But here again it is admittedly puzzling (at least to this reviewer) when, shortly after stating that Kazakhstan's oil fields and energy companies were purchased by international companies, Jäger unequivocally states (pg. 68), "it cannot be said that Kazakhstan's oil boom has an appeal to the country's population." Perspectives on the nation's natural wealth generally and oil development more specifically vary among members of the same communities and across the Republic, making claims for a nationally homogenous standpoint at a minimum problematic. Among, however, the author's more revealing insights is that economic migrants, drawn to the potential for higher pay in western Kazakhstan, recognize the promise is temporary and, according to the author, collectively migrants aspire to a more secure economic future outside the energy sector.

Tristam Barret's chapter six, "Notes on the Moral Economy of Gas in Present-day Azerbaijan," brings us back across the Caspian to begin with a description of a hillside outside of Baku, Azerbaijan frequented in the evenings particularly by tourists. For a small informal fee visitors can have a cup of tea and watch small tongues of flame burn along the hill. Even in Soviet times, Yanar Dağ (Fire Mountain) was known for its natural gas seepage, which could be ignited with a match and thrillingly spread by a casual toss of a rock. Payment to enter the grounds is a bit informal, located at the margin of formality and custom. Barret's depiction of Yanar DaÄ§ introduces some of the ambiguity that residents of Baku may encounter as they also navigate payment of their residential natural gas bills to collectors, "Gazoviki"-some of whom may extract unofficial payments from households. The author's discussion is incisive, including first-hand anecdotes from residents who were contending with a residential natural gas metering and fees collection system that was still in transition at the time the article was written. As with many other situations located at the interface of Azerbaijan's moral and political economy, Barret's analysis of first-hand experiences would be further nuanced with more consideration to roles played by gender; age; particular neighborhood location in Baku; and the varied personal relations that 
are co-constructed by residents and collectors. The author's discussion, however, is particularly illuminating when he examines the underlying Soviet-era Khozyaistvo ethos and contrasts this with the more blatant-rent seeking behavior experienced by a number of Baku's residents vis a vis individual Gazoviki.

More than 90 percent of the Kyrgyz territory is mountainous, considerably more than Switzerland's 60 percent-a European geopolitical reference sometimes employed in discussions of Kyrgyzstan's particular Central Asian location. But while the Swiss market in combination with its population's relative affluence facilitates use of heat pumps, appliance energy-efficiency deliberation in purchase decisions, solar panels and wood pellet stoves, the Kyrgyz population is more constrained in its energy consumption choices. Drawing principally on microeconomic data, contrasting Wooden's use of survey and qualitative interviews for her political ecology-influenced work in Kyrgyzstan (chapter three), Franziska Gassman and Raquel Tsukada explore prospects for Kyrgyz residential fuel substitution and energy consumption changes in chapter seven, "Switching Off or Switching Source: Energy Consumption and Household Response to Higher Energy Prices in the Kyrgyz Republic." Faced with increases in energy prices, the authors find-much as similar analyses have in other countries-that households will tend either to decrease their energy consumption or, if available, may switch to alternative sources of fuel with the possible concomitant environmental, household workload, and price effects. The authors point out, however, that fuel substitution is subject to Kyrgyz-specific infrastructural and household contexts, including rural and urban locations, mountainous and semi-mountainous settings, apartment or house residences, and reliability of electricity supply.

The collection's last chapter by Tobias Kraudzum, "Bottom-up and Top-down Dynamics of the Energy Transformation in the Eastern Pamirs of Tajikistan's Gorno Badakhshan Region," considers the household home heating challenges experienced in the Pamir mountains of the Republic of Tajikistan, Central Asia's other predominantly mountainous nation. The Soviet Union's Promethean drive to connect the high altitude Pamirs to the country's extensive energy infrastructure was unsuccessful; subsequent to the USSR's dissolution energy supply to the Pamirs' residents has remained fragmented, uncertain, and unsustainable. Residential energy supply is unevenly supplied by a mix of coal imported from the Kyrgyz Republic, animal manure, dwarf shrubs, low cost solar panels imported from China, and limited micro-hydro systems particularly operating in the western Pamirs. As indicated by Krudzum, potential exists for installation of decentralized hydro, solar, and wind turbines-with the technical and financial assistance of international and state agencies. Tactically implemented, this combination of small-scale energy production technologies could meet the electrical and thermal energy demands of the region's residents. The author's pessimistic conclusion, however, is that the combination of uncoordinated development programs, together with unreliable private investments, will not lead to a future of sustainable electrical and thermal energy supply for the residents of Tajikistan's Eastern Pamirs.

This collection of previously published articles brings together in a single and accessible volume a breadth of perspectives and insights that distinguishes it from other edited works on lives lived in the south Caucasus and Central Asia. It is important to note that some of the work by now is somewhat dated; there are no chapters on natural gas giant Turkmenistan nor water-thirsty Uzbekistan; and the editors curiously do not offer a concluding chapter that could help bridge the everyday energy politics from both sides of the Caspian-or conversely-that could indicate why such an endeavor would be flawed. However, as the evolving scholarly literature on the south Caucasus and Central Asia has tended to explore "Great Game" geopolitics and national policies, while popular accounts prefer references to Marco Polo and Genghis Khan, this collection refreshingly helps bring voice to stakeholders whose voices are too often hidden. 


\section{REFERENCES}

[1] Palazuelos E, Fernandez R. Kazakhstan: Oil endowment and oil empowerment. Communist and Post-Communist Studies 2012:45:27-37.

[2] Pleines H, Wöstheinrich R. 2016. The international-domestic nexus in anticorruption policy making: The case of Caspian oil and gas states. Europe-Asia Studies 2016:68:291-311.

[3] Bliss F. Poverty, governance and participation in Tajikistan. In Institutional Reform in Central Asia: Politico-economic Challenges, J Ahrens and HW Hoen (eds.), pp. 89-110. Routledge, Abingdon, 2013.

[4] Freeman, CP. New strategies for an old rivalry? China-Russia relations in Central Asia after the energy boom. Pacific Review 2018:31:635-654.

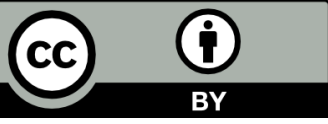

(C) The Author(s) 2019. This article is published under a Creative Commons Attribution (CC-BY) 4.0 International License. 